\title{
Avaliação dos capins mombaça e massai sob pastejo
}

\author{
Valéria Pacheco Batista Euclides ${ }^{1,2}$, Manuel Cláudio Motta Macedo ${ }^{1,2}$, Ademir Hugo \\ Zimmer $^{1}$, Liana Jank ${ }^{1,2}$, Marcelo Paschoal de Oliveira ${ }^{3}$ \\ ${ }^{1}$ Embrapa Gado de Corte, Rodovia Br 262, km 04, Caixa Postal 154, CEP: 79002-970, Campo Grande - MS. \\ 2 Bolsista do CNPq. \\ ${ }^{3}$ Assistente de Pesquisa, Embrapa Gado de Corte.
}

RESUMO - Visando à liberação para uso comercial, realizou-se avaliação do capim-massai (Panicum maximum) quanto à adaptação e produtividade. No plantio foram utilizados 2,7 t/ha de calcário dolomítico, $500 \mathrm{~kg} / \mathrm{ha}$ da fórmula 0-20-15 e 50 kg/ha de FTE BR-12. Como adubação de cobertura, efetuaram-se aplicações da fórmula 0-20-20 (200 kg/ha) e de nitrogênio (50 kg/ha de N). Os cultivares testados foram Mombaça e Massai. O delineamento experimental foi o de blocos casualizados com dois tratamentos e duas repetições. Os piquetes (1,5 ha) foram subdivididos em seis e submetidos ao pastejo rotacionado, com sete dias de utilização e 35 dias de descanso. Foram utilizados quatro animais-teste por piquete e animais reguladores para manter resíduos de MS pós-pastejo superiores a 2 t/ha. Os pastos foram amostrados no pré e no pós-pastejo para se estimarem a massa de forragem, a proporção dos componentes morfológicos e o valor nutritivo. Os animais foram pesados a cada 42 dias. Os animais no pasto de capim-mombaça ganharam mais peso (437 g/novilho.dia) que aqueles no pasto de capim-massai (300 g/novilho.dia). No entanto, o capim-massai suportou maior taxa de lotação (2,15 UA/ha) que o capim-mombaça (1,86 UA/ha). No entanto, esta maior capacidade de suporte não foi suficiente para compensar o menor ganho de peso vivo dos animais neste pasto (626 kg/ha.ano) em comparação àqueles mantidos no pasto de capim-mombaça (691 kg/ha.ano). O desempenho satisfatório, associado a outras importantes características de adaptação, torna o cultivar Massai uma forrageira promissora para a diversificação e viabilização da sustentabilidade de sistema de produção de bovinos de corte.

Palavras-chave: acúmulo de forragem, desempenho animal, oferta de forragem, seleção de cultivares, taxa de lotação, valor nutritivo

\section{Evaluation of Panicum maximum cvs Mombaça and Massai under grazing}

\begin{abstract}
A new cultivar of Panicum maximum (Massai) was evaluated for commercial release, at the Embrapa Beef Cattle, Campo Grande, MS, Brazil, from November 1993 to April 1999. At establishment, 2,7 t/ha of lime, $400 \mathrm{~kg} / \mathrm{ha}$ of 0-20-20 and $50 \mathrm{~kg} / \mathrm{ha}$ of FTE were applied. Maintenance fertilizer was $200 \mathrm{~kg} / \mathrm{ha}$ of 0-20-20 NPK and $50 \mathrm{~kg} / \mathrm{ha} \mathrm{N}$, annually. The Panicum maximum cultivars tested were Mombaça and Massai. The experimental design was a randomized complete block with two treatments and two replicates. The paddocks (1.5 ha) were divided in six, and submitted to a rotational stocking with 7 days of grazing and 35 days of rest. Four steers (testers) were kept in each paddock for a whole year and additional steers were allocated and removed from each paddock to assure post-grazing residues higher than $2 \mathrm{t} / \mathrm{ha}$ of dry matter. All pastures were sampled, before and after grazing, to estimate forage availability, percentages of the morphological components and nutritive value. The animals were weighed each 42 days. Steers grazing Mombaça pasture performed better than those grazing Massai pasture, averaging 437 and $300 \mathrm{~g} / \mathrm{steer} /$ day, respectively. However, the Massai pasture sustained higher stocking rate than the Mombaça pasture, with stocking rates of 2.15 and 1.86 AU/ha, respectively. This higher carrying capacity was not enough to compensate for the lower liveweight gain in the Massai pasture, resulting in lower productivity when compared to the Mombaça pasture, with averages of 626 and $691 \mathrm{~kg} / \mathrm{ha} /$ year, respectively. The satisfactory performance presented by cv Massai, associated with other important characteristics of adaptability, attest the value of this cultivar as an alternative pasture for different beef cattle systems as well as a contribution to their sustainability.
\end{abstract}

Key Words: animal performance, cultivar selection, forage accumulation, forage yield, stocking rate, nutritive value

\section{Introdução}

A manutenção de níveis de produção forrageira satisfatórios, compatíveis com o clima e as condições físico- químicas do solo de forma a manter o sistema sustentável ao longo do tempo constitui-se um dos grandes problemas da pecuária de corte. A busca da solução deste problema envolve não só a identificação de materiais forrageiros

Este artigo foi recebido em 20/10/2006 e aprovado em 13/7/2007.

Correspondências devem ser enviadas para val@cnpgc.embrapa.br 
adequados às diferentes condições, mas também que sejam componentes integrantes do sistema de produção. Para isso, é necessário que apresentem boa qualidade nutricional e, principalmente, que possam produzir adequadamente em condições de pastejo.

A espécie Panicum maximum Jacq. é originária da África tropical até a África do Sul, em margens florestais, onde ocupa solo recém-desmatado e em pastagens sob sombra rala de árvores. Seu habitat abrange altitudes desde o nível do mar até 1.800 m. Em 1982, a Embrapa Gado de Corte recebeu do ORSTOM (hoje IRD) toda sua coleção de P. maximum, composta de 426 acessos (Jank, 1995). Dos 156 acessos de $P$. maximum avaliados na primeira fase na Embrapa Gado de Corte, $40 \%$ produziram mais e apresentaram melhor estacionalidade de produção que o cultivar Colonião (Jank et al., 1994). Desses acessos, os 25 melhores foram avaliados em uma Rede de Ensaios Regionais. Foram selecionados os sete melhores (Jank et al., 1994), que foram avaliados sob pastejo, em pequenas parcelas, das quais foram liberados dois cultivares, Tanzânia e Mombaça. Além desses lançamentos, outros acessos tiveram características importantes, entre eles, o BRA-007102, lançado comercialmente como cv. massai, que se mostrou promissor e bem adaptado à região do Cerrado (Euclides et al., 1995) e, portanto, pode contribuir para a maior diversificação forrageira e para a sustentabilidade dos sistemas de produção.

Assim, os objetivos foram comparar os cultivares Massai e Mombaça (Panicum maximum) quanto à persistência sob pastejo, a capacidade de suporte e as produções por animal e por área e avaliar se o capim-massai possui mérito para diversificação e sustentabilidade de sistemas de produção de bovinos de corte.

\section{Material e Métodos}

O experimento foi realizado na Embrapa Gado de Corte, Campo Grande, MS, no período de novembro de 1993 a abril de 1999.
O padrão climático da região é descrito, segundo Köppen, como pertencente à faixa de transição entre Cfa e Aw tropical úmido. A precipitação média anual é de $1.560 \mathrm{~mm}$ (Figura 1) e o período de seca inclui os meses de maio a setembro, quando ocorrem $30 \%$ da precipitação anual.

O solo da área experimental é classificado como Latossolo Vermelho Distrófico.Após a derrubada do cerrado e o preparo do solo, procedeu-se à correção e adubação com calcário dolomítico $(\mathrm{PRNT}=73 \%)(2,7 \mathrm{t} / \mathrm{ha})$, com a fórmula 0-20-15 (500 kg/ha) e FTE BR-12 (9,0\% de Zn; 1,8\% de $\mathrm{B} ; 0,8 \%$ de $\mathrm{Cu} ; 3,0 \%$ de Fe; $2,0 \%$ de $\mathrm{Mn}$ e $0,10 \% \mathrm{Mo}$ ), na quantidade de $50 \mathrm{~kg} / \mathrm{ha}$. Foram semeadas sementes puras viáveis, na quantidade de $2 \mathrm{~kg} /$ ha por cultivar. Após a cobertura das sementes com uma gradagem leve, foi feita compactação do solo.

Anualmente, em outubro, efetuou-se em cobertura aplicação da fórmula 0-20-20 (200 kg/ha) e, em novembro, realizou-se adubação com nitrogênio $(50 \mathrm{~kg} / \mathrm{ha})$ na forma de uréia. Em setembro de 1995 e 1997, aplicou-se calcário dolomítico $($ PRNT $=80 \%)$ em cobertura $(1,2$ e 2,0 t/ha, respectivamente).

Os cultivares de $P$. maximum testados foram Mombaça e Massai (BRA-007102). O delineamento experimental foi o de blocos casualizados com dois tratamentos e duas repetições.

Os pastos foram implantados em fevereiro de 1994, mas, por problemas operacionais, o pastejo só foi iniciado em novembro, assim, esses pastos ficaram sob pastejo até abril, quando os animais foram substituídos. O experimento iniciou-se em maio de 1995. Os piquetes de 1,5 ha foram subdivididos em seis e manejados sob lotação intermitente, com sete dias de utilização e 35 dias de descanso. Cada piquete foi pastejado por quatro novilhos (animais de prova), distribuídos ao acaso, e por animais reguladores, da mesma categoria, colocados e removidos de cada piquete de acordo com a disponibilidade de forragem. Anualmente, em maio, os animais foram substituídos por outros da mesma categoria.

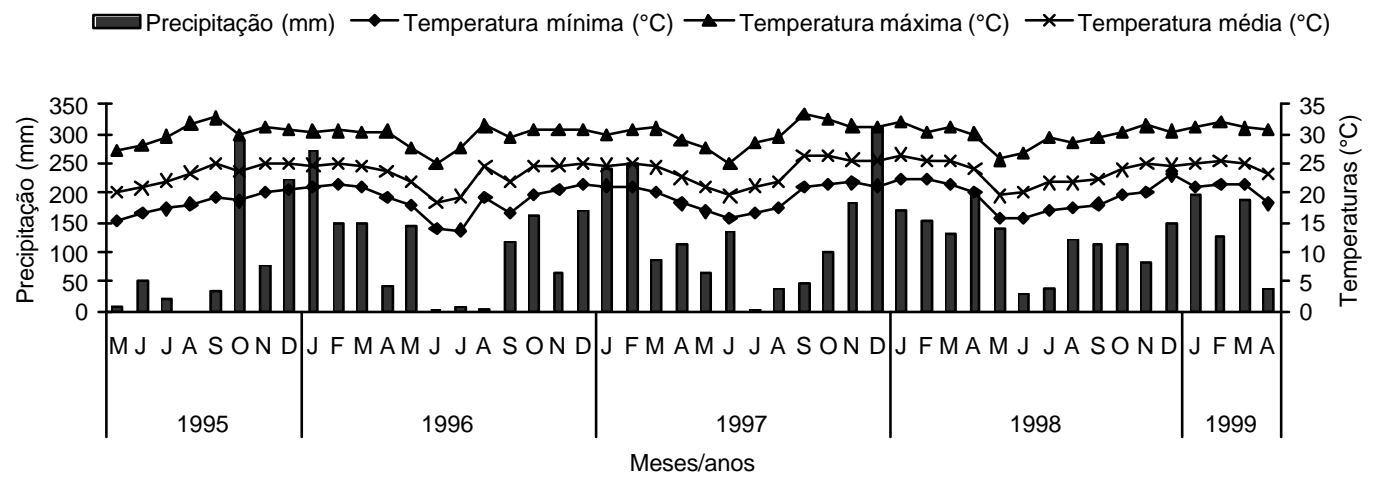

Figura 1 - Temperaturas máxima, média e mínima e distribuição da precipitação pluviométrica no período de maio de 1995 a abril de 1999. 


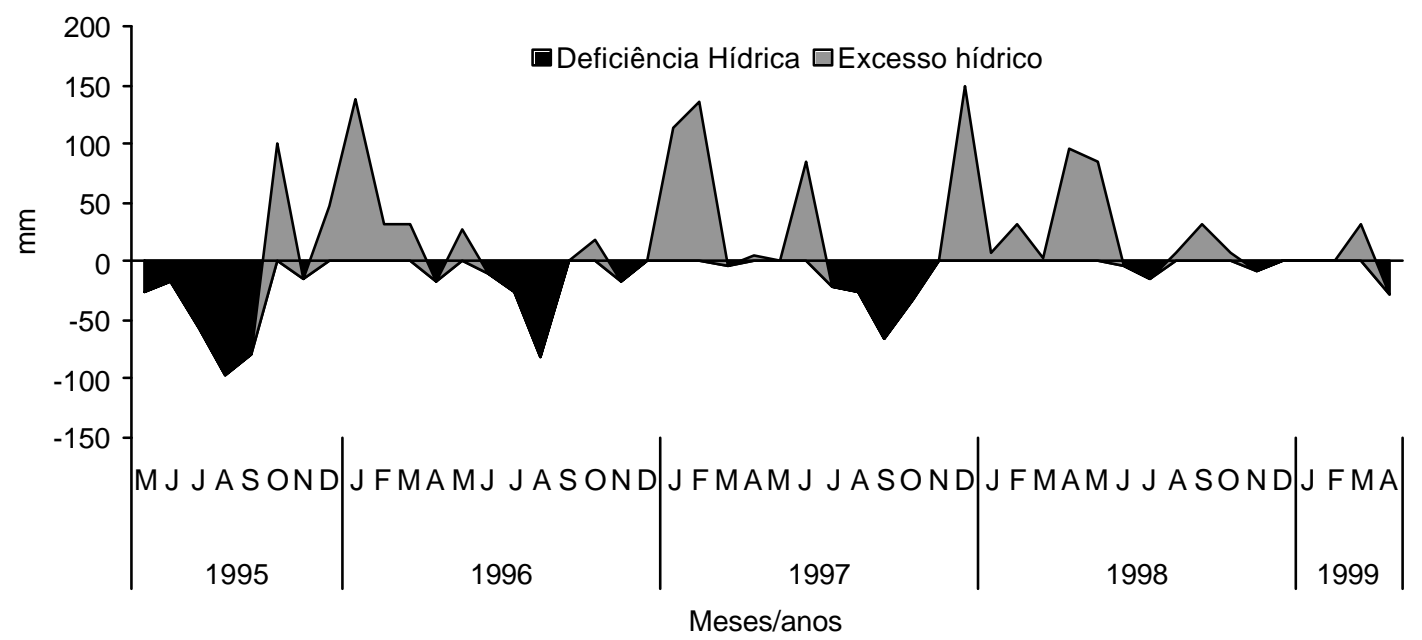

Figura 2 - Extrato do balanço hídrico mensal durante o período de maio de 1995 a abril de 1999.

Os pastos foram amostrados no pré e no pós-pastejo. Para se estimar a massa de forragem, foram cortadas ao acaso, a $15 \mathrm{~cm}$ do solo, 24 amostras em cada piquete. As amostras foram divididas em duas; uma das subamostras foi seca e pesada e a outra foi separada em lâmina foliar, colmo (bainha e colmo) e material morto. A proporção de cada componente morfológico foi expressa como porcentagem do peso total. Adicionalmente, em cada piquete, no pré e no pós-pastejo, foram coletadas duas amostras simulando o pastejo animal para se estimar o valor nutritivo.

Os teores de PB, FDN e lignina em detergente ácido e a digestibilidade in vitro da MO foram estimados utilizando-se a espectroscopia de reflectância do infravermelho próximo (NIRS), de acordo com os procedimentos de Marten et al. (1985). Os dados de reflectância das amostras na faixa de comprimentos de onda de 1100 a $2.500 \mathrm{~mm}$ foram armazenados por um espectrômetro (modelo NR5000: NIRSsystems, Inc., USA) acoplado a um microcomputador.

A cada 42 dias, todos os animais foram pesados após jejum de 15 horas. Os animais de prova estimaram a qualidade do pasto quanto ao ganho de peso diário. Também foi computado o número de dias que os animais adicionais foram mantidos na pastagem. Assim, os animais-teste e os adicionais, combinados, possibilitaram estimativas da capacidade suporte e de produção por área.

Ao final do experimento, estimaram-se, visualmente, as porcentagens de solo descoberto, de invasoras e de Brachiaria decumbens utilizando-se de 20 quadrados de $1 \mathrm{~m}^{2}$ por piquete.

Os dados foram agrupados por épocas do ano, de maio a setembro e de outubro a abril, e analisados por um modelo matemático contendo os efeitos fixos de gramíneas, blocos, período do ano e ano de avaliação e as interações entre esses fatores. O ganho médio diário e a taxa de lotação também foram analisados sem o agrupamento, considerando no modelo os meses de avaliação.

Todas as análises foram feitas pelo método dos quadrados mínimos utilizando-se o procedimento General Linear Model, disponível no SAS Institute (1996). Os comandos RANDOM e TEST foram utilizados para identificação e realização dos testes apropriados para cada variável independente. A comparação de médias foi realizada pelo teste Tukey adotando-se nível de significância de 5\%. No caso de interações significantes, a comparação de média foi realizada por meio de contrastes, adotando-se 5\% de significância.

Para os acúmulos de matéria seca verde e de lâminas foliares, o mês foi analisado como variável contínua. Com base em análises prévias, selecionou-se o polinomial de maior ordem para cada variável dependente.

\section{Resultados e Discussão}

No pré-pastejo, o capim-massai apresentou maiores $(\mathrm{P}<0,01)$ massas de matéria seca total $(\mathrm{MST})$ e de matéria seca verde (MSV), maior porcentagem de material morto $(\mathrm{PMM})$, menor $(\mathrm{P}<0,01)$ porcentagem de colmo $(\mathrm{PCo}) \mathrm{e}$ porcentagem de lâmina foliar (PLF) semelhante $(\mathrm{P}=0,97) \mathrm{em}$ comparação ao capim-mombaça: $3,5 \pm 0,084$ e 2,6 $\pm 0,082 \mathrm{t} / \mathrm{ha}$ de MST; 2,0 $\pm 0,084$ e 1,7 $\pm 0,081$ t/ha de MSV; 45,5 $\pm 1,79$ e $36,3 \pm 1,75 \%$ de PMM; $12,7 \pm 0,75$ e 22,8 $\pm 0,72 \%$ de PCo; e $41,81,79$ e 40,9 $\pm 1,75 \%$ de PLF. Também houve efeitos de ano experimental $(\mathrm{P}<0,05)$ e da interação $(\mathrm{P}<0,05)$ ano $\times$ período do ano (Tabela 1), no entanto, não foram observadas interações cultivar $\times$ ano $(\mathrm{P}>0,11)$ e cultivar $\times$ período do ano $(\mathrm{P}>0,10)$ para as massas de forragem e seus componentes morfológicos. 
As forrageiras não crescem uniformemente ao longo do ano. Além de variações de temperatura e fotoperíodo, a estacionalidade das chuvas, característica das regiões tropicais, não permite produção uniforme de forragem durante o ano. Para ambos os cultivares, a curva que melhor descreveu as taxas de acúmulo de MSV e de lâminas foliares (LF) foi a cúbica $(\mathrm{P}<0,01)$. Assim, os maiores acúmulos de forragem ocorreram no verão, os intermediários nos meses de primavera e outono e os mais baixos nos meses de inverno (Figura 3). Comportamentos semelhantes foram observados para os acúmulos líquidos de lâminas foliares em capimmombaça (Carnevalli et al., 2006) e em capim-tanzânia (Barbosa et al., 2007). O efeito da estacionalidade no capimmombaça foi maior que no capim-massai (Figura 3).

Além dessas variações nas taxas de acúmulo da forrageira, foram observadas alterações nas características morfológicas dos pastos. Apesar de a MST ter sido semelhante $(\mathrm{P}>0,10)$ entre períodos das águas e seco, 3,2 $\pm 0,08$ e 2,9 $\pm 0,10$ t/ha, respectivamente, no período das águas, a MSV e PLF foram maiores $(\mathrm{P}<0,01)$ que no período seco, com valores de $2,5 \pm$ 0,09 e $1,1 \pm 0,07 \mathrm{t} / \mathrm{ha} ; 57,8 \pm 1,1$ e 24,0 $\pm 1,4 \%$, respectivamente.

O padrão de variação das características dos pastos no pós-pastejo foi semelhante ao do pré-pastejo, ou seja, o capim-massai apresentou maiores $(\mathrm{P}<0,01)$ massas de MST e MSV, maior PMM, menor ( $\mathrm{P}<0,01)$ PCo e PLF semelhante $(\mathrm{P}=0,28)$ ao do capim-mombaça: $2,8 \pm 0,064 \mathrm{e} 1,9 \pm 0,062 \mathrm{t} / \mathrm{ha}$ de MST; $1,1 \pm 0,052$ e $0,9 \pm 0,051$ t/ha de MSV; $62,1 \pm 1,81$ e $54,8 \pm 1,76 \%$ de PMM; $11,4 \pm 1,24$ e $20,6 \pm 1,21 \%$ de PCo e $26,5 \pm 1,81$ e $24,5 \pm 1,76 \%$ de PLF, provavelmente porque optou-se por deixar maior disponibilidade de forragem para o cultivar Massai, uma vez que os animais não estavam apresentando o desempenho esperado nos pastos de P. maximum, espécie de alta qualidade (Euclides, 2000). Procurou-se, assim, aumentar a oportunidade de seleção de dieta de melhor valor nutritivo.

Exceto para MST $(\mathrm{P}=0,26)$, houve efeito do período do ano $(\mathrm{P}<0,01)$ sobre a MSV e os componentes morfológicos no pós-pastejo. Também foram observadas diferenças $(\mathrm{P}<0,01)$ nas massas de MST e MSV entre os anos, o que não ocorreu para as porcentagens dos componentes morfológicos (P>0,22). À exceção da PLF $(\mathrm{P}>0,18)$, houve interação também $(\mathrm{P}<0,05)$ entre período do ano e ano experimental para as demais variáveis (Tabela 1). Para massa de MSV e as porcentagens de lâmina foliar e de colmo, observou-se interação $(\mathrm{P}<0,02)$ cultivares $\times$ período do ano (Tabela 2$)$.

Não houve efeitos das interações cultivar $\times$ período do ano $(\mathrm{P}>0,25)$, cultivar $\times$ ano experimental $(\mathrm{P}>0,96)$, período do ano $\times$ ano experimental $(\mathrm{P}>0,12)$, cultivar $\times$ cultivar, período do ano $\times$ ano experimental $(\mathrm{P}>0,41)$ sobre as taxas de lotação (TL). No entanto, o capim-massai suportou maior $(\mathrm{P}<0,01)$ taxa de lotação $(2,15 \pm 0,08 \mathrm{UA} / \mathrm{ha})$ em comparação ao capim-mombaça $(1,86 \pm 0,08 \mathrm{UA} / \mathrm{ha})$. Independentemente do cultivar, os pastos suportaram maior $(\mathrm{P}<0,01)$ taxa de lotação $(2,92 \pm 0,07 \mathrm{UA} / \mathrm{ha})$ durante o período das águas em comparação ao período seco $(1,1 \pm 0,09$ UA/ha). Essa variação na taxa de lotação foi conseqüência do manejo adotado, pois foi ajustada de acordo com a massa de forragem. Como a grande proporção de forragem foi produ zida no período das águas (Figura 3), ambos os cultivares suportaram elevado número de animais neste período, reduzindo drasticamente esse número durante o período seco (Figura 4). Foram observadas também diferenças entre ano

Tabela 1 - Massas de matéria seca total (MST) e matéria seca verde (MSV) e porcentagens de lâmina foliar (PLF), colmo (PCo) e material morto (PMM) em pastos dos capins massai e mombaça antes e após o pastejo nos períodos seco e das águas

\begin{tabular}{|c|c|c|c|c|c|c|c|c|}
\hline & \multicolumn{4}{|c|}{ Período das águas } & \multicolumn{4}{|c|}{ Período seco } \\
\hline & $95 / 96$ & $96 / 97$ & $97 / 98$ & $98 / 99$ & $95 / 96$ & $96 / 97$ & $97 / 98$ & $98 / 99$ \\
\hline \multicolumn{9}{|l|}{ Pré-pastejo } \\
\hline $\operatorname{MST}(\mathrm{kg} / \mathrm{ha})$ & $2.987 b(164)$ & $2.592 \mathrm{~b}(160)$ & $3.468 \mathrm{a}(150)$ & $3.741 \mathrm{a}(150)$ & $3.841 \mathrm{a}(183)$ & $3.042 b(211)$ & $1.923 \mathrm{c}(211)$ & $2.895 \mathrm{~b}(211)$ \\
\hline MSV (kg/ha) & $2.317 \mathrm{a}(138)$ & $2.062 b(135)$ & $2.754 \mathrm{a}(126)$ & $2.861 \mathrm{a}(126)$ & $1.313 \mathrm{a}(154)$ & $1.350 \mathrm{a}(179)$ & $660 b(179)$ & $1.168 \mathrm{a}(179)$ \\
\hline PLF $(\%)$ & $55,6 \mathrm{~b}(2,22)$ & $57,6 \mathrm{ab}(2,18)$ & $61,4 \mathrm{a}(1,64)$ & $56,5 \mathrm{ab}(2,04)$ & $19,7 \mathrm{~b}(2,50)$ & $20,5 \mathrm{~b}(2,88)$ & $25,8 \mathrm{ab}(2,88)$ & $30,0 \mathrm{a}(2,88)$ \\
\hline $\mathrm{PCo}(\%)$ & $22,8 \mathrm{a}(1,46)$ & $21,6 \mathrm{a}(1,43)$ & $16,8 \mathrm{~b}(1,33)$ & $20,2 \mathrm{ab}(1,34)$ & $17,4 b(1,64)$ & $26,5 \mathrm{a}(1,89)$ & $9,75 \mathrm{c}(1,89)$ & $12,1 \mathrm{bc}(1,89)$ \\
\hline PMM (\%) & $21,6 \mathrm{a}(2,47)$ & $20,7 \mathrm{a}(2,42)$ & $22,8 \mathrm{a}(2,25)$ & $23,3 \mathrm{a}(2,25)$ & $62,9 \mathrm{a}(2,76)$ & $53,0 \mathrm{~b}(3,19)$ & $64,4 \mathrm{a}(3,19)$ & $54,9 \mathrm{~b}(3,19)$ \\
\hline \multicolumn{9}{|l|}{ Pós-pastejo } \\
\hline $\operatorname{MST}(\mathrm{kg} / \mathrm{ha})$ & $2.627 \mathrm{a}(118)$ & $1.891 b(115)$ & $2.449 \mathrm{a}(108)$ & $2.629 \mathrm{a}(108)$ & $2.675 \mathrm{a}(132)$ & $2.548 \mathrm{a}(152)$ & $1.616 b(152)$ & $2.337 \mathrm{a}(152)$ \\
\hline MSV (kg/ha) & $1437 a(85)$ & $1001 b(83)$ & $1416 a(78)$ & $1451 \mathrm{a}(78)$ & $780 \mathrm{a}(95)$ & $568 \mathrm{a}(110)$ & $303 b(110)$ & $776 a(110)$ \\
\hline PLF (\%) & $34,3 \mathrm{a}(2,35)$ & $34,6 \mathrm{a}(2,40)$ & $34,8 \mathrm{a}(2,14)$ & $33,8 \mathrm{a}(2,14)$ & $13,8 \mathrm{a}(2,63)$ & $14,1 \mathrm{a}(3,03)$ & $15,6 \mathrm{a}(3,03)$ & $23,1 \mathrm{a}(3,03)$ \\
\hline $\operatorname{PCo}(\%)$ & $21,1 \mathrm{a}(1,78)$ & $20,2 \mathrm{a}(1,73)$ & $23,4 \mathrm{a}(1,62)$ & $21,6 \mathrm{a}(1,62)$ & $14,7 \mathrm{a}(1,99)$ & $11,5 \mathrm{a}(2,29)$ & $4,3 \mathrm{~b} 65,6 \mathrm{~b}$ & $11,3 \mathrm{a} 65,6 \mathrm{~b}$ \\
\hline PMM (\%) & $44,6 \mathrm{a}(2,96)$ & $45,2 \mathrm{a}(2,89)$ & $41,8 \mathrm{a}(2,70)$ & $44,6 \mathrm{a}(2,70)$ & $71,5 \mathrm{ab}(3,31)$ & $74,4 \mathrm{ab}(3,82)$ & $80,1 \mathrm{a}(3,82)$ & $65,6 b(3,82)$ \\
\hline
\end{tabular}

Médias, na mesma linha e dentro de período do ano seguidas de letras diferentes, são diferentes $(P<0,05)$ pelo teste Tukey.

Valores entre parênteses referem-se ao erro-padrão da média. 


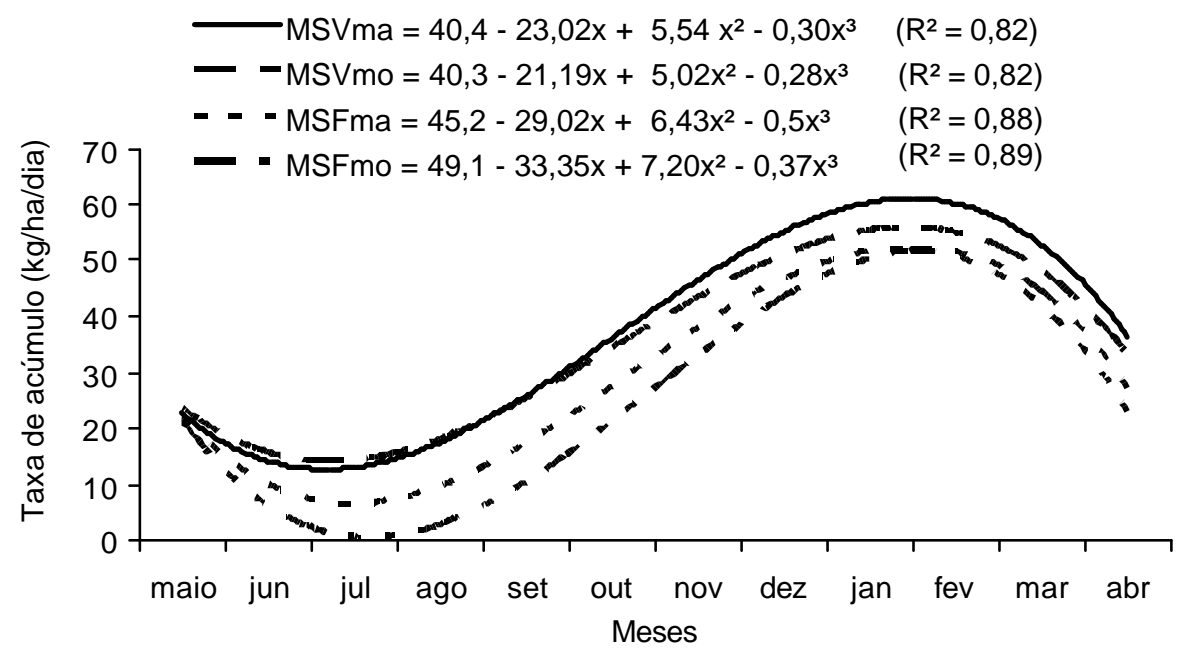

Figura 3 - Taxas de acúmulo de matéria seca verde (MSV) e de lâmina foliares (MSF) de pastos de capins massai (ma) e mombaça (mo), de acordo com os meses do ano.

Tabela 2 - Massas de matéria seca total (MST) e de matéria seca verde (MSV) e porcentagens de lâmina foliar, colmo e material morto dos resíduos pós-pastejo de pastos de capins massai e mombaça nos períodos seco e das águas

\begin{tabular}{lccccc}
\hline & \multicolumn{2}{c}{ Período das águas } & & \multicolumn{2}{c}{ Período seco } \\
\cline { 2 - 3 } \cline { 5 - 6 } & Massai & Mombaça & & Massai & Mombaça \\
\hline MST (kg/ha) & $2.839 \mathrm{a}$ & $1.959 \mathrm{~b}$ & & 2.755 & $1.833 \mathrm{~b}$ \\
& $(79)$ & $(80)$ & & $(104 \mathrm{a})$ & $(104)$ \\
MSV (kg/ha) & $1.513 \mathrm{a}$ & $1.139 \mathrm{~b}$ & & $621 \mathrm{a}$ & $592 \mathrm{a}$ \\
& $(57)$ & $(57)$ & & $(75)$ & $(75)$ \\
Lâmina foliar (\%) & $38,3 \mathrm{a}$ & $30,4 \mathrm{~b}$ & & $14,7 \mathrm{a}$ & $18,6 \mathrm{a}$ \\
& $(1,57)$ & $(1,59)$ & & $(2,08)$ & $(2,08)$ \\
Colmo (\%) & $15,4 \mathrm{~b}$ & $27,8 \mathrm{a})$ & & $7,4 \mathrm{~b}$ & $13,5 \mathrm{a}$ \\
& $(1,19)$ & $(1,20)$ & & $(1,57)$ & $(1,57)$ \\
Material morto (\%) & $46,3 \mathrm{a}$ & $41,8 \mathrm{a}$ & & $77,9 \mathrm{a}$ & $67,8 \mathrm{~b}$ \\
& $(1,97)$ & $(2,00)$ & & $(2,61)$ & $(1,57)$ \\
\hline
\end{tabular}

Médias, na mesma linha e dentro de período do ano, seguidas de letras diferentes são diferentes $(P<0,05)$ pelo teste Tukey.

Valores entre parênteses se referem ao erro-padrão da média.

experimental $(\mathrm{P}<0,02)$, uma vez que as taxas de lotação foram semelhantes nos três primeiros anos, que foram superiores à do quarto ano experimental, com médias de 2,$40 ; 2,43 ; 2,36$ e 2,00 $\pm 0,11 \mathrm{UA} / \mathrm{ha}$, respectivamente.

A independência entre a massa de MST e o consumo de forragem foi observada por Euclides et al. (1999) em três cultivares de $P$. maximum. Esses autores encontraram correlação positiva entre massa de LF e ingestão de forragem pelos animais. Optou-se, portanto, por expressar a oferta de forragem ( $\mathrm{kg}$ de forragem/100 $\mathrm{kg}$ de peso corporal, PC) considerando apenas esta fração.

As ofertas de lâmina foliar (LF) foram semelhantes entre os cultivares $(\mathrm{P}=0,07)$ e entre os períodos do ano $(\mathrm{P}=0,18)$ : 32 e $26 \pm 2,2 \mathrm{~kg}$ de $\mathrm{LF} / 100 \mathrm{~kg}$ de $\mathrm{PC} /$ dia para os cultivares
Massai e Mombaça, respectivamente; e $31 \pm 1,9$ e $27 \pm 2,5 \mathrm{~kg}$ de MSV/100 kg PC/dia para os períodos das águas e da seca, respectivamente. Não foram observados efeitos das interações cultivar $\times$ período do ano $(\mathrm{P}=0,32)$; cultivar $\times$ ano $(\mathrm{P}=0,88)$; ano $\times$ período do ano $(\mathrm{P}=0,12)$; e cultivar $\times$ ano $\times$ período do ano $(\mathrm{P}=0,90)$. No entanto, houve efeito do ano experimental $(\mathrm{P}<0,01)$, uma vez que as ofertas foram semelhantes entre o primeiro, o segundo e o terceiro ano de pastejo e inferiores às do quarto ano, cujas médias foram $23 \pm 3,0 ; 29 \pm 3,3 ; 25 \pm 3,1$ e $38 \pm 3,2 \mathrm{~kg}$ de $\mathrm{LF} / 100 \mathrm{~kg}$ $\mathrm{PC} / \mathrm{dia}$, respectivamente. Pode-se depreender desses resultados que o ajuste da taxa de lotação durante o quarto ano não foi adequado.

Durante todo o período experimental, as ofertas de LF foram superiores às encontradas por Almeida et al. (2000a), que verificaram aumento linear na ingestão MS de capimelefante anão até $13 \%$ do PC de oferta de LF, e por Gontijo Neto et al. (2006), que observaram, em capim-tanzânia, ingestão máxima de MS quando a oferta de LF foi de $20 \%$ do PC. Portanto, a disponibilidade de LF provavelmente não foi fator limitante do consumo e do desempenho animal.

Não houve efeito das interações cultivar $\times$ ano experimental $(\mathrm{P}>0,35)$ e cultivar $\times$ período $\times$ ano experimental $(\mathrm{P}>0,11)$ sobre as variáveis associadas ao valor nutritivo dos pastos. No entanto, foram observadas diferenças entre cultivares $(\mathrm{P}<0,01)$, período do ano $(\mathrm{P}<0,01)$ e suas interações $(\mathrm{P}<0,01)$ nos períodos pré e pós-pastejo (Tabela 3 ).

De modo geral, os teores de PB e a digestibilidade in vitro da MO (DIVMO) do capim-mombaça foram maiores que do capim-massai e foram superiores no período das águas. Entre períodos do ano, as variações foram maiores entre os cultivares (Tabela 3 ). Os resultados encontrados 

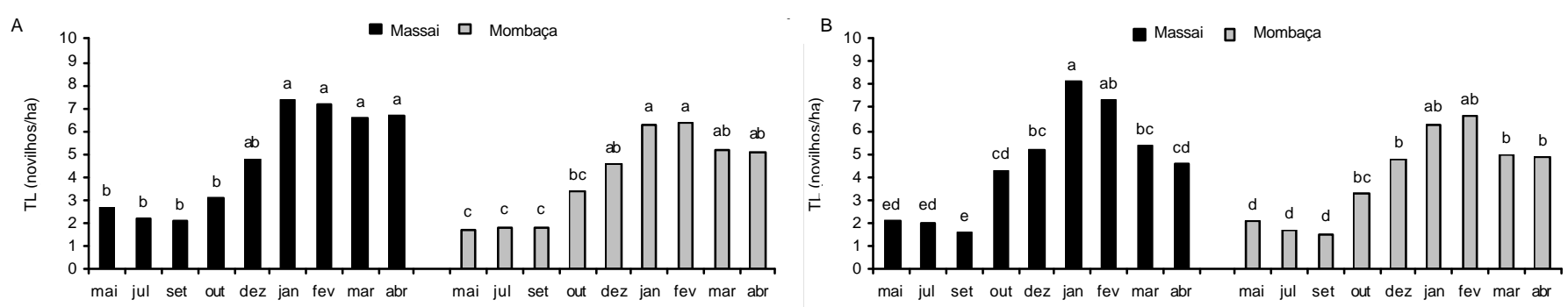

C
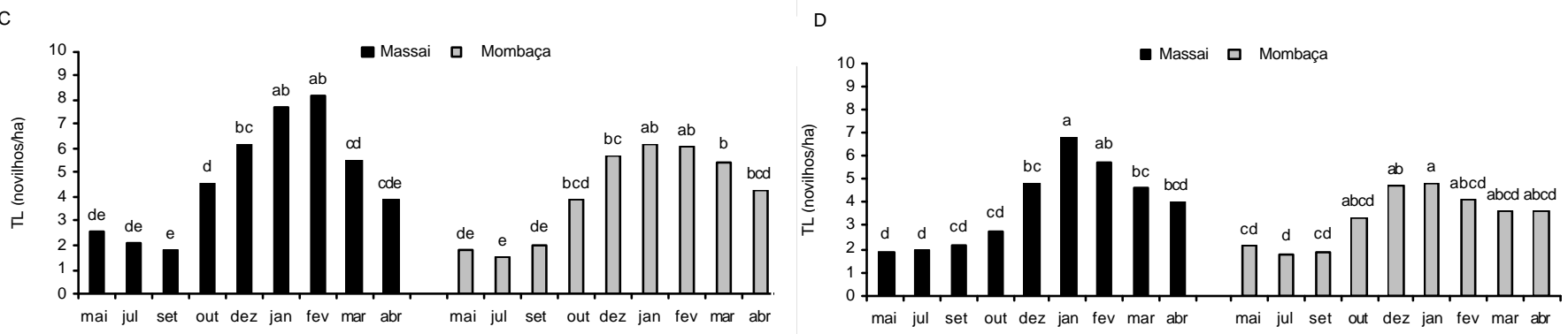

Figura 4 - Taxas de lotação (TL, novilhos de $250 \mathrm{~kg}$ ) de pastos dos capins massai e mombaça nos anos de 1995/1996 (A), 1996/1997 (B), 1997/1998 (C) e 1998/1999 (D).

Médias seguidas de letras diferentes são diferentes $(P<0,05)$ pelo teste Tukey.

para o capim-mombaça foram semelhantes aos descritos por Bueno (2003) para esse mesmo cultivar em condição de 95\% de interceptação luminosa do dossel forrageiro. Tanto no período das águas quanto no da seca, ambos os cultivares apresentaram alto teor de FDN (Tabela 3), característica de forrageiras tropicais (Euclides, 2000).

Os animais no pasto de capim-mombaça ganharam mais peso $(\mathrm{P}<0,01), 437 \pm 11 \mathrm{~g} /$ novilho/dia, que aqueles no pasto de capim-massai, $300 \pm 11 \mathrm{~g} /$ novilho/dia. O pior desempenho dos animais nos pastos de capim-massai pode ser explicado pelo menor valor nutritivo desse cultivar (Tabela 3), pela maior freqüência de estrutura Girder I, um arranjo de células esclerenquimáticas entre as células epidérmicas e da bainha do feixe vascular, nas LF de capim-massai em comparação às de capim-mombaça (Lempp et al., 2000). Segundo esses autores, após 72 horas de digestão de LF do capim-massai, observou-se alta freqüência de bainhas do feixe vascular intactas e fragmentos laminares ainda estruturados, indicando que, nas lâminas foliares de Massai, existe alguma restrição à digestão, confirmada pela menor DIVMO (Tabela 3).

Além disso, segundo Lempp et al. (2000), esse tipo de estrutura atrasa ou impede a remoção da epiderme por digestão ou por força física, limitando o consumo voluntário pelos animais. No entanto, Brâncio et al. (2003) não observaram diferenças na ingestão de MS por animais em pastos de capins massai e mombaça, tanto no período das águas quanto no da seca. Contudo, provavelmente ocorreu menor ingestão de nutrientes digestíveis (IND), pois,
Tabela 3 - Teores de proteína bruta (PB), digestibilidade in vitro da matéria orgânica (DIVMO), fibra em detergente neutro (FDN) e lignina em detergente ácido (LDA) de amostras de pastos dos capins massai e mombaça antes e após o pastejo nos períodos das águas e da seca

\begin{tabular}{lccccc}
\hline & \multicolumn{2}{c}{ Período das águas } & & \multicolumn{2}{c}{ Período seco } \\
\cline { 6 - 6 } \cline { 5 - 6 } & Massai & Mombaça & & Massai & Mombaça \\
\hline Pré-pastejo & & & & \\
PB (\%) & $9,7 \mathrm{~b}$ & $12,6 \mathrm{a}$ & & $8,0 \mathrm{~b}$ & $9,9 \mathrm{a}$ \\
& $(0,26)$ & $(0,26)$ & & $(0,36)$ & $(0,37)$ \\
DIVMO (\%) & $58,7 \mathrm{~b}$ & $62,8 \mathrm{a}$ & & $52,3 \mathrm{~b}$ & $58,1 \mathrm{a}$ \\
& $(0,67)$ & $(0,67)$ & & $(0,93)$ & $(0,96)$ \\
FDN (\%) & $75,9 \mathrm{a}$ & $74,5 \mathrm{~b}$ & & $76,1 \mathrm{a}$ & $73,4 \mathrm{~b}$ \\
& $(0,26)$ & $(0,26)$ & & $(0,36)$ & $(0,37)$ \\
LDA (\%) & $2,5 \mathrm{a}$ & $2,6 \mathrm{a}$ & & $3,0 \mathrm{a}$ & $2,6 \mathrm{~b}$ \\
& $(0,06)$ & $(0,06)$ & & $(0,07)$ & $(0,09)$ \\
\hline Pós-pastejo & & & & \\
PB (\%) & $7,9 \mathrm{~b}$ & $10,7 \mathrm{a}$ & & $5,7 \mathrm{~b}$ & $7,9 \mathrm{a}$ \\
& $(1,25)$ & $(1,11)$ & & $(1,09)$ & $(1,37)$ \\
DIVMO (\%) & $50,7 \mathrm{~b}$ & $54,5 \mathrm{a}$ & & $43,7 \mathrm{~b}$ & $50,3 \mathrm{a}$ \\
& $(1,50)$ & $(1,33)$ & & $(1,33)$ & $(1,63)$ \\
FDN (\%) & $77,4 \mathrm{~b}$ & $78,3 \mathrm{a}$ & & $80,1 \mathrm{a}$ & $77,6 \mathrm{~b}$ \\
& $(0,49)$ & $(0,53)$ & $(0,55)$ & $(0,84)$ \\
LDA (\%) & $3,3 \mathrm{~b}$ & $3,8 \mathrm{a}$ & & $3,7 \mathrm{~b}$ & $4,4 \mathrm{a}$ \\
& $(0,08)$ & $(0,09)$ & $(0,11)$ & $(0,14)$ \\
\hline
\end{tabular}

Médias, na mesma linha e dentro de período do ano, seguidas de letras diferentes são diferentes $(P<0,05)$ pelo teste Tukey.

Valores entre parênteses se referem ao erro-padrão da média

segundo Minson (1990), existe alta correlação entre IND e ganho por animal.

Independentemente do cultivar, os animais ganharam mais peso $(\mathrm{P}<0,04)$ durante o período das águas $(510 \pm 17 \mathrm{~g} /$ 
novilho/dia) em comparação ao período seco $(80 \pm 25 \mathrm{~g} /$ novilho/dia). Não foram observados efeitos das interações cultivar $\times$ ano experimental $(\mathrm{P}=0,97)$, cultivar $\times$ período do ano $(\mathrm{P}=0,46)$ e cultivar $\times$ período do ano $\times$ ano experimental $(\mathrm{P}=0,22)$ nem efeito de ano experimental $(\mathrm{P}=0,14)$ sobre o GMD. Brâncio et al. (2003), em experimento com esses cultivares na mesma área experimental, observaram que os consumos médios de MS foram de 2,3 e 2,8\% do PC nos períodos da seca e das águas, respectivamente. Assim, o menor ganho de peso durante o período seco foi conseqüência do menor valor nutritivo da dieta (Tabela 3) e, provavelmente, da menor ingestão de forragem durante esse período.

A taxa de lotação e o ganho médio diário também foram analisados considerando o efeito do mês do ano. Nesse caso, houve interação $(P<0,01)$ cultivar $\times$ mês $\times$ ano experimental. As médias de ganho de peso (Figura 5) em pastos de capins mombaça e massai foram, respectivamente, de 590 e $435 \mathrm{~g} /$ novilho/dia no período das águas e de 130 e $29 \mathrm{~g} /$ novilho/dia no período seco. O ganho obtido para o capimmombaça durante o período das águas situou-se entre os 704 e 546 g/novilho/dia obtidos por Cândido et al. (2005) quando a condição de pré-pastejo do capim-mombaça esteve associada a 2,5 folhas expandidas por perfilho e a 3,5 folhas expandidas por perfilho, respectivamente.

A progressiva desfolha do dossel no decorrer do período de pastejo (Tabela 1) teve reflexo negativo no valor nutritivo dos pastos. Houve decréscimos $(\mathrm{P}<0,01)$ nos teores de PB e DIVMO e acréscimos $(\mathrm{P}<0,01)$ nos conteúdos de FDN e LDA (Tabela 3). Assim, o valor nutritivo da dieta selecionada pelo animal provavelmente esteve entre os valores registrados no pré e no pós-pastejo.
O consumo voluntário de forragem pelo animal é controlado pelo valor nutritivo da forragem apenas se a quantidade de forragem disponível não for limitante. No entanto, a oferta de LF foi sempre superior a $20 \mathrm{~kg} / 100 \mathrm{~kg}$ de PC/dia, indicando que esse não foi um fator limitante (Gontijo Neto et al., 2006). Contudo, os valores nutritivos (Tabela 3) dos pastos foram inadequados ou insuficientes para atender às demandas nutricionais dos animais e resultaram em desempenhos inferiores ao potencial de ganho de peso desses animais (Figura 5).

Uma vez que os consumos médios de MS pelos animais pastos dos capins mombaça e massai foram de 2,8 e de $2,0 \mathrm{~kg}$ de MS/100 kg PV nos períodos das águas e da seca, respectivamente (Brâncio et al., 2003), e que o conteúdo de extrato etéreo destas forrageiras é muito pequeno, a quantidade de nutrientes digestíveis totais foi estimada por meio da DIVMO. De acordo com o NRC (2000), durante o período das águas, o capim-mombaça fornece PB suficiente para ganho de 900 $\mathrm{g} /$ dia, entretanto, a energia foi insuficiente (Tabela 3) para manter este ganho. No capim-massai, as quantidades de proteína e energia (Tabela 3 ) foram suficientes para promover ganhos de 300 a 700g/dia. No período seco, o valor nutritivo do capim-mombaça foi suficiente para promover ganhos de 0 a 300g/dia (NRC, 2000), enquanto a perda de peso nos animais em pasto de capim-massai pode ser explicada pelo baixo conteúdo de energia e pela deficiência de proteína do capim, uma vez que, no fim do período de pastejo, o conteúdo de PB estava abaixo do valor crítico (Tabela 3). Nesse caso, a atividade dos microrganismos do rúmen é reduzida ocasionando decréscimo nas taxas de digestão e passagem do alimento e no consumo voluntário. Em gramíneas tropicais, este valor se mantém entre 6e 7\% de PB na dieta(Minson,1990).
A
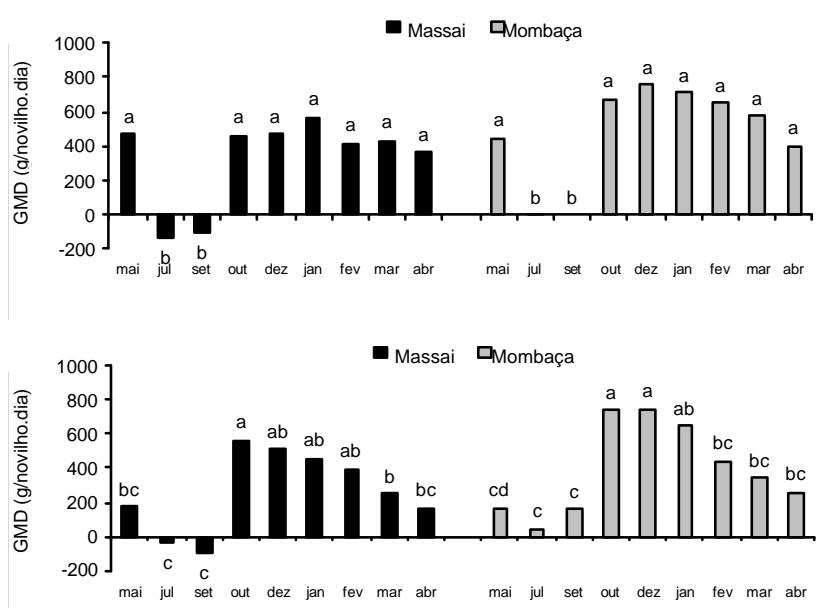

B
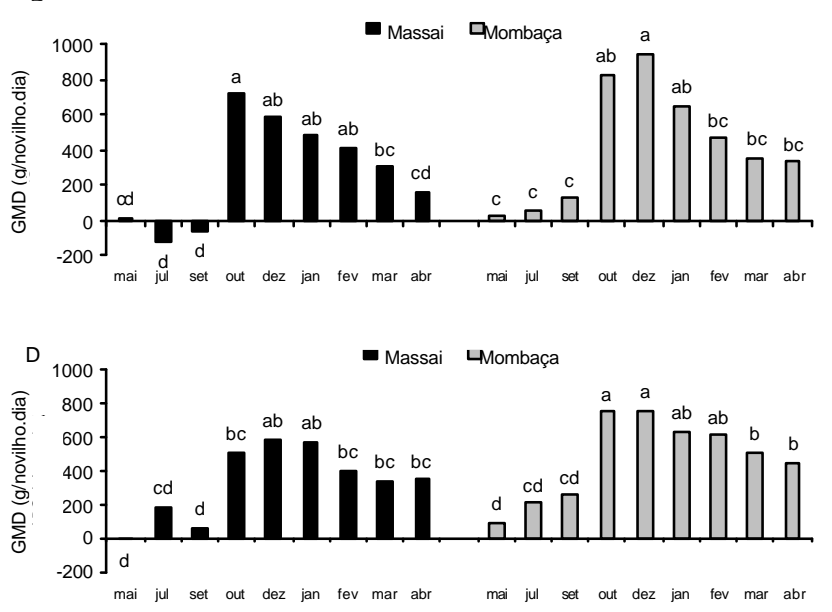

Figura 5 - Ganho médio diário (GMD) dos animais em pastos de capins massai e mombaça nos anos de 1995/1996 (A), 1996/1997 (B), 1997/1998 (C) e 1998/1999 (D).

Médias seguidas de letras diferentes são diferentes $(P<0,05)$ pelo teste Tukey. 
Qualquer decréscimo no consumo voluntário tem efeito significativo sobre a eficiência de produção. Neste contexto, deve-se considerar o alto conteúdo de FDN destas forrageiras (Tabela 3), tanto no período seco quanto no das águas, pois a FDN está relacionada diretamente ao efeito de enchimento do rúmen, um mecanismo de controle do consumo voluntário, e inversamente à concentração energética da dieta (Mertens, 1994).

Além dos fatores nutricionais relacionados aos aspectos inerentes ao valor nutritivo e a fatores metabólicos, o consumo de forragem por animais em pastejo pode ser controlado por fatores não nutricionais relacionados ao comportamento ingestivo (Poppi et al., 1987). Neste contexto, as características estruturais do pasto que influenciam a facilidade de seleção e preensão da forragem tornam-se importantes. Apesar dos decréscimos na relação lâmina foliar:colmo (LFC) do período das águas para o da seca, a redução na relação lâmina foliar:material morto (LFM) foi muito maior (Tabela 4). Possivelmente, durante o período seco, os animais tiveram maiores dificuldades na seleção e preensão da forrageira, uma vez que altas proporções de colmo e/ou material morto podem limitar o consumo, mesmo quando a disponibilidade de MS é alta. Assim, o baixo desempenho animal durante o período seco (Figura 5) foi conseqüência do baixo valor nutritivo (Tabela 3 ) associado ao baixo consumo de forragem pelos animais.

A maior capacidade de suporte no pasto de capimmassai não foi suficiente para compensar o menor ganho de peso dos animais, o que resultou em menor $(\mathrm{P}<0,01)$ produtividade (626 kg/ha.ano) em comparação ao pasto de capimmombaça $(691 \pm 21 \mathrm{~kg} /$ ha.ano $)$.

A produtividade do capim-massai manteve-se praticamente estável $(\mathrm{P}=0,22)$, com ganhos de peso corporal de 640 a $600 \mathrm{~kg} / \mathrm{ha}$.ano de PC, enquanto a do capim-mombaça decresceu $(\mathrm{P}<0,07)$ nos dois últimos anos de avaliação, com ganhos de PC de 725, 747, 666 e $628 \mathrm{~kg} /$ ha.ano, respectivamente, para o primeiro, segundo, terceiro e quarto anos de avaliação. Na análise de solo da camada arável, verificou-se redução nos teores médios de $\mathrm{P}$ disponível no extrator de Mehlich-1, comprovando a seguinte dinâmica: 1,70; 2,79; 2,21; 3,35; 1,98 e 1,71 mg/dm nos anos de 1994 (antes da adubação de estabelecimento), 1994 (depois da adubação), 1995, 1996, 1997 e 1998, respectivamente, apesar da adubação anual de cobertura com a fórmula 0-20-20 (200 kg/ha) de 1995 em diante. Assim, a dose de P205, principalmente na adubação de manutenção, deve ser aumentada para manter o potencial de produção no capim-mombaça em latossolos argilosos da região do Cerrado.

Após cinco anos da implantação, o pasto de capimmassai apresentou menor $(\mathrm{P}<0,01)$ área de solo descoberto e menores $(\mathrm{P}<0,01)$ porcentagens de invasoras de folha larga e de Brachiaria decumbens quanto comparado ao capim-mombaça: em média, 12,5 e 24,6\%; 0,45 e 1,22\%; e 0 e $1,15 \%$, respectivamente.

Apesar de o desempenho animal verificado no pasto do cultivar Massai ter sido inferior ao obtido com o cultivar Mombaça, esse cultivar, em comparação ao capim-mombaça, possui melhor cobertura de solo e maior tolerância ao decréscimo de P no solo. Além disso, essa gramínea teve maior produção de parte aérea e de raízes em soluções com alta concentração de alumínio, em comparação aos cultivares Mombaça e Tanzânia (Almeida et al., 2000b), características que podem ser confirmadas pelo desenvolvimento de seu sistema radicular mais adaptado às condições adversas do solo, como compactação, fertilidade e acidez.

Outro aspecto importante de adaptação dessa forrageira está relacionado à sua resistência à cigarrinha-das-pastagens. Embrapa Gado de Corte (2001) avaliou alguns cultivares de $P$. maximum quanto à resistência à cigarrinha Notuzulia entreriana e verificou baixos níveis de sobrevivência e prolongados períodos ninfais para o capimmassai, caracterizando-o como pouco adequado ao desenvolvimento desse inseto. O percentual médio de sobrevivência foi de 7,7\%, igual ao do capim-tanzânia (10\%) e inferior ao do capim-mombaça (39\%) e do capim-tobiatã (37\%). Além disso, a maior resistência a $N$. entreriana foi confirmada pela sua maior duração média do período ninfal, de 41, 32,5, 29,3 e 30,5 dias para os cultivares Massai, Tanzânia, Mombaça e Tobiatã, respectivamente. Esse maior nível de resistência foi confirmado pelos resultados

Tabela 4 - Relações lâmina foliar:colmo (LF:C) e lâmina foliar:material morto (LF:M) de pastos de capins massai e mombaça antes e após o pastejo nos períodos da seca e das águas

\begin{tabular}{lcccccc}
\hline & \multicolumn{2}{c}{ Período das águas } & & \multicolumn{2}{c}{ Período seco } \\
\cline { 2 - 3 } \cline { 6 - 7 } & Massai & Mombaça & & Massai & Mombaça \\
\hline Pré-pastejo & & & & & \\
LF:C & $4,7: 1 \mathrm{a}$ & $2,5: 1 \mathrm{~b}$ & & $3,6: 1 \mathrm{a}$ & $1,6: 1 \mathrm{~b}$ \\
& $(0,33)$ & $(0,33)$ & & $(0,43)$ & $(0,43)$ \\
LF:M & $2,8: 1 \mathrm{~b}$ & $4,3: 1 \mathrm{a}$ & & $0,4: 1 \mathrm{a}$ & $0,5: 1 \mathrm{a}$ \\
& $(0,34)$ & $(0,34)$ & & $(0,45)$ & $(0,45)$ \\
\hline
\end{tabular}

Pós-pastejo

$\begin{array}{lllll}\text { LF:C } & 3,1: 1 \mathrm{a} & 1,4: 1 \mathrm{~b} & 3,3: 1 \mathrm{a} & 1,9: 1 \mathrm{~b} \\ & (0,29) & (0,30) & (0,39) & (0,39) \\ \text { LF:M } & 1,1: 1 \mathrm{a} & 1,0: 1 \mathrm{a} & 0,2: 1 \mathrm{a} & 0,3: 1 \mathrm{a} \\ & (0,11) & (0,17) & (0,14) & (0,14)\end{array}$

Médias, na mesma linha e dentro de período do ano, seguidas de letras diferentes são diferentes $(P<0,05)$ pelo teste Tukey.

Valores entre parênteses referem-se ao erro-padrão da média. 
obtidos no cultivar Massai, de baixos níveis populacionais de adultos e ninfas no campo. Igualmente, Valério et al. (2000) constataram menor taxa de excreção de fêmeas de $N$. entreriana nesse cultivar ( $1.141 \mathrm{mg} / 24$ horas) em relação aos demais cultivares avaliados: Tanzânia (1653 mg/24 horas), Mombaça (1681 mg/24 horas) e Tobiatã (2331 mg/ 24 horas).

\section{Conclusões}

A produdividade animal em pastos de capim-mombaça foi maior que a obtida em pastos de capim-massai. Para manter a maior produtividade animal em pastos de capimmombaça, a adubação fosfatada de manutenção deve ser o suficiente para manter os teores de $\mathrm{P}$ no solo, pelo extrator de Mehlich-1, acima de $4 \mathrm{mg} / \mathrm{dm}^{3}$. O desempenho animal satisfatório proporcionado pelo cultivar Massai, associado à melhor cobertura do solo, à menor presença de invasoras e à maior tolerância ao decréscimo de $\mathrm{P}$ no solo, torna esse cultivar uma forrageira promissora para a diversificação e a sustentabilidade de sistemas de produção de bovinos de corte.

\section{Literatura Citada}

ALMEIDA, E.X.; MARASCHIN, G.E.; HARTHMANN, O.E.L. et al. Oferta de forragem de capim-elefante anão 'Mott' e o rendimento animal. Revista Brasileira de Zootecnia, v.29, n. 5, p.1288-1295, 2000a.

ALMEIDA, A.A.S.; MONTEIRO, F.A.; JANK, L. Avaliação de Panicum maximum Jacq. para tolerância ao alumínio em solução nutritiva. Revista Brasileira de Ciência do Solo, v.24, n.2, p.339-334, 2000b.

BARBOSA, R.A.; NASCIMENTO JR., D.; EUCLIDES, V.P.B. et al. Capim-tanzânia submetidos a combinações entre intensidade e freqüência de pastejo. Pesquisa Agropecuária Brasileira, v.42, n.3, p.329-340, 2007.

BRÂNCIO, P.A.; NASCIMENTO JR., D.; EUCLIDES, V.P.B. et al. Avaliação de três cultivares de Panicum maximum Jacq. sob pastejo: composição da dieta, consumo de matéria seca e ganho de peso animal. Revista Brasileira de Zootecnia, v.32, n.5, p.1037-1044, 2003.

BUENO, A.A.O. Características estruturais do dossel forrageiro, valor nutritivo e produção de forragem em pastos de capim-mombaça submetidos a regimes de desfolhação intermitente. Piracicaba: Escola Superior de Agricultura Luiz de Queiroz, 2003. 124p. Dissertação (Mestrado) Piracicaba, Escola Superior de Agricultura Luiz de Queiroz, 2003. Disponível em: < http://www.teses.usp.br/teses/disponiveis/11/ 11139/tde-28072003-142554> Acesso em: 16/5/2007.

CÂNDIDO, M.J.D.; ALEXANDRINO, E.; GOMIDE, C.A.M. et al. Período de descanso, valor nutritivo e desempenho animal em pastagem de Panicum maximum cv. Mombaça sob lotação intermitente. Revista Brasileira de Zootecnia, v.34, n.5, p.1449-1458, 2005.

CARNEVALLI, R.A.; DA SILVA, S.C.; OLIVEIRA, A.A. et al. Herbage produdtion and grazing losses in Panicum maximum cv. Mombaça pastures under four grazing managements. Tropical Grasslands, v.40, n.3, p.165-176, 2006.

EMBRAPA GADO DE CORTE. Capim-massai (Panicum maximum cv. Massai: alternativa para diversificaçãp de pastagem. Campo Grande: Embrapa Gado de Corte, 2001, 9p. (Comunicado técnico, n. 69). Diponível em http:<// www.cnpgc.embrapa.br/publicacoes/cot/COT69.html> Acesso em: 16/5/2007

EUCLIDES, V.P.B. Alternativas para intensificação da produção de carne bovina em pastagem. Campo Grande: Embrapa Gado de Corte, 2000. 65p.

EUCLIDES, V.P.B.; MACEDO, M.C.M.; OLIVEIRA, M.P. Avaliação de ecotipos de Panicum maximum sob pastejo em pequenas parcelas. In: REUNIÃO ANUAL DA SOCIEDADE BRASILEIRA DE ZOOTECNIA, 32., 1995, Brasília. Anais... Brasília: Sociedade Brasileira de Zootecnia, 1995. p.97-99.

EUCLIDES, V.P.B.; THIAGO, L.R.S.; MACEDO, M.C.M. Consumo voluntário de forragem de três cultivares dePanicum maximum sob pastejo. Revista Brasileira de Zootecnia, v.28, n.6, p.1177-1185, 1999.

GONTIJO NETO, M.M.; EUCLIDES, V.P.B.; NASCIMENTO JR., D. et al. Consumo e tempo diário de pastejo por novilhos Nelore em pastagem de capim-tanzânia sob diferentes ofertas de forragem. Revista Brasileira de Zootecnia, v.35, n.1, p.60-66, 2006.

JANK, L.; SAVIDAN, Y.H.; SOUZA, M.T. de et al. Avaliação do germoplasma de Panicum maximum introduzido na África. 1. Produção forrageira. Revista da Sociedade Brasileira de Zootecnia, v.23, n.3, p.433-440, 1994.

JANK, L. Melhoramento e seleção de variedades de Panicum maximum. In: SIMPÓSIO SOBRE MANEJO DA PASTAGEM, 12., 2005, Piracicaba. Anais... Piracicaba: Fundação de Estudos Agrários Luiz de Queiroz, 1995. p.21-58.

LEMPP, B.; EUCLIDES, V.P.B.; MORAIS, M.G. et al. Avaliações do resíduo da digestão de três cultivares de Panicum maximum. In: REUNIÃO ANUAL DA SOCIEDADE BRASILEIRA DE ZOOTECNIA, 37., 2000, Viçosa, MG. Anais... Viçosa, MG: Sociedade Brasileira de Zootecnia [2000]. (CD-ROM).

MARTEN, G.C.; SHENK, J.S.; BARTON II, F.E. Near infrared reflectance spectroscopy (NIRS), analysis quality. Washington: USDA, 1985. 110p. (Agriculture Handbook, 643).

MERTENS, D.R. Regulation of forage intake. In: FAHEY JR., G.C. (Ed.) Forage quality evaluation and utilization. Madison: American Society of Agronomy; Crop Science Society of America; Soil Science Society of America, 1994. p.450-493.

MINSON, D.J. Forage in ruminant nutrition. San Diego: Academic Press, 1990. 483p.

NATIONAL RESEARCH COUNCIL - NRC. Nutrient requirement of beef cattle. 7.rev.ed. Washington, D.C.: National Academy Press, 2000. 242p.

POPPI, D.P.; HUGHES, T.P.; L'HUILLIER, P.J. Intake of pasture by grazing ruminants. In: NICOL, A.M. (Ed.). Livestock feeding on pasture. Hamilton: New Zealand Society of Animal Production, 1987. p.55-64. (Occasional Publication, 10).

STATISTICAL ANALYSIS SYSTEM - SAS. SAS/STAT software: changes and enhancements throughout release 6.11. Cary: 1996. (CD-ROM). 